\title{
Políticas do olhar: feminismo e cinema em Laura Mulvey
}

\author{
Sônia Weidner Maluf \\ Universidade Federal de Santa Catarina \\ Cecilia Antakly de Mello \\ Birkbeck College (Bolsista Capes) \\ Vanessa Pedro \\ Birkbeck College (Bolsista Capes) e Universidade \\ Federal de Santa Catarina
}

\begin{abstract}
A produção intelectual de Laura Mulvey, ${ }^{1}$ em seus escritos e nos filmes que realizou, pode ser resumida a partir de uma preocupação central, a produção de uma crítica feminista ao cinema narrativo tradicional e a ruptura com seus regimes de prazer visual, única possibilidade de construção de um contra-cinema. Seus principais trabalhos se desenvolveram em duas grandes vertentes: a crítica à relação entre imagem e olhar predominante no cinema narrativo clássico ${ }^{2}$ e a construção de outras possibilidades

\footnotetext{
Copyright (c) 2005 by Revista Estudos Feministas

1 Crítica, cineasta, feminista e atualmente professora e pesquisadora do Birkbeck College, em Londres.

2 O cinema narrativo clássico se desenvolveu nos estúdios de Hollywood durante as primeiras décadas do século XX. É chamado de clássico devido a sua influência duradoura sobre o cinema americano e mundial. Pode ser definido como um sistema de regras e convenções que controlam a narrativa - personagens individuais como agentes causais, tempo subordinado à estrutura de causa-efeito, tendência à objetividade e à resolução dos conflitos no final. A técnica cinematográfica também se desenvolveu de modo a servir a uma narrativa linear. Mulvey, em sua reflexão, opera uma distinção entre o que ela denomina cinema narrativo e cinema de vanguarda, ou contra-cinema. Algumas autoras têm questionado essa divisão, ponderando que o "sistema do cinema clássico" é uma abstração, na medida em que cada filme excede o sistema e não pode ser reduzido a este (Kaja SILVERMAN, 1988, p. ix) ou que, mesmo criticando-se os princípios da narrativa e do cinema narrativo, esta narrativa não pode ser totalmente abandonada pelo cinema de vanguarda, e no caso pelo cinema feminista (ver Teresa DE LAURETIS, 1984, p. 157).
} 
de olhar e de outras linguagens do desejo, a partir do projeto de um cinema de vanguarda, ou contra-cinema - incluindo aí a idéia de um cinema feminista. Foi, no entanto, a primeira vertente de sua crítica - a crítica ao olhar masculino - que acabou ganhando mais visibilidade.

Este ano, seu trabalho mais conhecido, o artigo "Visual Pleasure and Narrative Cinema", completa 30 anos de sua primeira publicação, na revista Screen. ${ }^{3}$ Além de ser um marco para os estudos feministas do cinema e para os estudos de cinema como um todo, esse é certamente um dos trabalhos mais publicados, traduzidos e citados da área ${ }^{4}$ e considerado por algumas um dos mais importantes textos da crítica feminista do cinema. ${ }^{5}$ Desde sua primeira edição o artigo, segundo a própria autora, "ganhou vida própria" 6 e, apesar de ter sido escrito com propósitos mais políticos do que acadêmicos, como ela reconhece na entrevista à REF, tem feito uma longa carreira nos estudos de cinema - e em geral, como acontece com todo texto fundador, tem sido lido como uma obra em si, fora do contexto dos próprios trabalhos posteriores de Mulvey.

As duas referências teóricas predominantes nos trabalhos de Mulvey são a psicanálise e o feminismo. É através deste último que a psicanálise, em diversas leituras combinada com - marxismo, entra na agenda política do pós-60.7 Mas é sobretudo a disposição crítica e política dos estudos feministas que interfere na leitura e na recepção da psicanálise nesse período e na formação de uma nova vertente teórica e crítica nos estudos de cinema. ${ }^{8}$ A compreensão das dimensões psíquicas da cultura popular combina-se com o projeto político de tornar visível os mecanismos inconscientes da relação entre imagem e olhar. ${ }^{9}$

Em "Visual Pleasure...", Laura Mulvey busca na teoria psicanalítica os fundamentos para uma profunda crítica da imagem - sobretudo à produzida no contexto do cinema hollywoodiano - como um produto da predominância do olhar masculino, ao qual corresponderia a imagem da mulher como objeto passivo do olhar. A teoria psicanalítica é utilizada como uma "arma política" para desmascarar as formas como "o

\footnotetext{
${ }^{3}$ MULVEY, 1975

${ }^{4}$ No Brasil, o artigo foi publicado na coletânea $A$ experiência do cinema, organizada por Ismail Xavier (XAVIER, 1983).

${ }^{5}$ Ver DE LAURETIS, 1984, p. 58.

${ }^{6}$ MULVEY, 1989a, p. vii.

7 Ver MULVEY, 1996a.

${ }^{8}$ Ver, por exemplo, DE LAURETIS, 1984, p. 3. Para Jaqueline ROSE, 1986, p. 2 e 6, é também através dos estudos de cinema e do feminismo que a psicanálise lacaniana chega à vida intelectual inglesa, e sobretudo o feminismo colocou desafios políticos à psicanálise.

9 Além de Mulvey, Claire Johnston e Pam Cook são outras duas referências fundamentais na introdução da psicanálise para a análise feminista do cinema nos anos 1970. Ver COOK e JOHNSTON, 1988 [1974].
}

344 Estudos Feministas, Florianópolis, 13(2): 343-350, maio-agosto/2005 
inconsciente da sociedade patriarcal ajuda a estruturar a forma do cinema". ${ }^{10}$ Utilizando-se de conceitos freudianos como escopofilia, voyeurismo, complexo de castração, narcisismo e, sobretudo, fetichismo, o artigo estabelece o que seria 0 mecanismo de prazer e plenitude do cinema narrativo de ficção e propõe a ruptura desse mecanismo, a destruição dessa forma de prazer e a produção de uma "nova linguagem do desejo". Nesse artigo, as posições masculina e feminina - e a divisão heterossexista ativo/passivo: o homem é o olhar; a mulher, a imagem - são claramente demarcadas na análise da imagem e do olhar no cinema. Essas posições são, no entanto, complicadas pela noção de complexo de castração, na qual a mulher representa a falta e a ameaça de castração representa a diferença sexual. Para Mulvey, o inconsciente masculino tem duas possibilidades de escapar dessa ansiedade de castração: colocando a mulher em uma posição desvalorizada, de alguém que deve ser salvo ou punido (voyeurismo), ou, pela completa negação da castração, substituindo ou transformando a figura feminina por/em um fetiche - este é o mecanismo da escopofilia fetichista, bastante visível no culto da estrela de cinema.

No artigo "Afterthoughts on 'Visual Pleasure..."' ela introduz dois novos elementos à sua análise: a mulher como espectadora e a personagem feminina como centro da narrativa. Nesse artigo, focado na análise do filme Duel in the Sun e na ambigüidade da heroína feminina (entre a "feminilidade" e a "masculinidade"), os pressupostos centrais de "Visual pleasure..." são mantidos. No entanto, ela toca mais diretamente no tema da mulher na audiência e deixa mais explícito que o olhar masculino, mais do que o "olhar do homem", representa uma posição, um lugar. Ao falar em "olhar masculino", ela está falando da masculinização da posição do espectador, e da masculinidade como ponto-de-vista, ${ }^{11}$ e da mulher na posição de espectadora assumindo o lugar masculino do olhar e do prazer, revivendo o que seria para a psicanálise o aspecto perdido de sua sexualidade, ou seja, a fase ativa, fálica e pré-simbólica da vida sexual. Aqui, evidentemente, Mulvey está se referindo à teoria de Freud sobre a "feminilidade" e à constituição da subjetividade feminina como uma travessia para a passividade, na qual a fase ativa permaneceria como simples memória.

A análise de Mulvey de que no cinema narrativo tradicional o olhar (e a subjetividade) é masculino, ativo e fálico ${ }^{12}$ acabou servindo de lastro para grande parte da teoria

\footnotetext{
${ }^{10}$ MULVEY, 1989b [1975], p. 14.

${ }^{11}$ Ver MULVEY, 1989c.

12 Ver Introdução em SCREEN, 1992.
} 
e da crítica feminista do cinema. Numerosas leituras, reinterpretações e críticas a essa tese do olhar como masculino foram produzidas no campo da crítica feminista do cinema grande parte dessas críticas focadas no que seria a ausência de uma reflexão sobre um "olhar feminino" que pudesse ser contraposto ao masculino. Mary Ann Doane, ${ }^{13}$ por exemplo, explora outros modelos para interpretar a justaposição entre diferença sexual e diferenças no olhar. Ela desloca a oposição ativo/passivo na análise de Mulvey para a dicotomia distância/ proximidade. Haveria, para a espectadora feminina, uma sobrepresença da imagem; ela seria a própria imagem. A possibilidade de superação dessa proximidade - que impede a realização do processo semiótico (e do conhecimento) por completo - seria romper com o voyerismo e o fetichismo ligados ao espectador masculino. Doane utiliza o conceito de mascarada de Joan Rivière para descrever duas formas dessa ruptura: uma ostentação excessiva de feminilidade, que pode ser agora assumida e usada como uma máscara; ${ }^{14}$ e a apresentação da personagem feminina como portadora e controladora do olhar. A mascarada ajudaria a simular a distância crítica necessária entre a espectadora e a personagem - entre si mesma e sua própria imagem. Para Ann Kaplan, a psicanálise, ao mesmo tempo que é um instrumento importante para a análise feminista, pode ser um discurso opressor na medida em que coloca as mulheres em uma posição que é contraditória com a possibilidade de se tornarem sujeitos e com a possibilidade de autonomia. Para ela é fundamental que sejam colocadas questões sobre se o olhar é necessariamente masculino e se seria possível construir outras estruturas em que as mulheres portariam o olhar sem necessariamente estarem na posição masculina. ${ }^{15} \mathrm{Kaja}$ Silverman questiona em que sentido, representada somente como um objeto do discurso masculino, a mulher é ou pode ser um sujeito. ${ }^{16}$ Teresa de Lauretis, em um ensaio instigante sobre desejo e narrativa, inspirado na relação feita por Mulvey entre sadismo e narrativa, aprofunda o argumento desta, mas abre um espaço para uma crítica menos pessimista ao indagar o quanto o cinema de vanguarda deveria ou não abandonar a narrativa, ponderando que os trabalhos mais interessantes atualmente no cinema não são nem anti-narrativos, nem antiedípicos. Um outro tema a ser explorado é o quanto o rompimento com a matriz heterossexual da sexualidade não desestabilizaria a idéia de uma imagem feminina correspondendo a um olhar masculino. Como a pergunta de

\footnotetext{
13 DOANE, 1992.

14 Joan RIVIÈRE apud DOANE, 1992.

${ }^{15}$ KAPLAN, 1983.

16 SILVERMAN, 1988.
} 
Judith Butler ${ }^{17}$ em relação à música cantada por Aretha Franklin, "you make me feel like a natural woman" - e se quem escuta for uma mulher? Ou seja, o que significaria - tanto para a produção quanto para a interpretação das imagens no cinema - a introdução de um desejo que escape da heteronormatividade. Jackie Stacey, por exemplo, discute a questão do redimensionamento da discussão sobre o olhar considerando os prazeres especificamente homossexuais da mulher espectadora e a necessidade de repensar a rígida distinção entre desejo e identificação. ${ }^{18}$

Algumas dessas questões foram desenvolvidos pela própria Laura Mulvey em trabalhos mais recentes. A possibilidade de um "olhar feminino", não colonizado, é justamente a vertente menos conhecida e talvez só desenvolvida posteriormente nos escritos de Mulvey - apesar de já estar presente nos filmes que ela realizou junto com Peter Wollen entre o final dos anos 70 e o início dos 80 .

Nos seus primeiros escritos, reunidos na coletânea Visual and Other Pleasures, predomina o projeto de construir um campo crítico ao cinema narrativo clássico, denunciando o caráter fetichista e ilusório da relação olhar-imagem e propondo a ruptura e a destruição do prazer provocado por esse tipo de relação. As estruturas da psiquê - sobretudo aquelas relacionadas com a sexualidade - entram aqui como um elemento fundamental para a compreensão dos mecanismos ideológicos e discursivos das sociedades do espetáculo.

Em trabalhos posteriores, sobretudo os reunidos na coletânea Fetishism and Curiosity, publicada em 1996, ela desenvolve mais a fundo uma teoria do fetichismo e contrapõe a este outra forma de olhar, figurada por uma leitura feminista do mito de Pandora e sua curiosidade irresistível. Nesse artigo ela busca dar mais complexidade ao argumento de "Visual Pleasure...", discutindo a idéia de uma "estética da curiosidade"19 para além da oposição binária entre o olhar masculino e a imagem feminina. O olhar de Pandora sobre a caixa seria o oposto do olhar masculino pela imagem da mulher fetichizada do cinema. A caixa representa o espaço proibido do universo feminino e o inefável da sexualidade feminina. ${ }^{20}$ Sua leitura, em diálogo com o projeto de reinterpretação feminista da iconografia do feminino, provoca uma transformação do mito, que inicialmente teria um significado misógino (a mulher como origem dos males do mundo). A curiosidade de Pandora é explorada em suas dimensões

\footnotetext{
${ }^{17}$ BUTLER, 1991

${ }^{18}$ STACEY, 1992

${ }^{19}$ MULVEY, 1996b, p. 59.

${ }^{20}$ MULVEY, 1996b.
} 
políticas, como forma de "deciframento da imagem", uma curiosidade mais de saber do que de simplesmente ver, que Mulvey irá denominar epistemofilia, em oposição à escopofilia fetichista. Sua tese central nesse artigo pode ser sintetizada assim: "Enquanto curiosidade é um desejo compulsivo de ver e saber, de investigar algo secreto, fetichismo é sustentado por uma recusa de ver, por uma recusa em aceitar a diferença que o corpo feminino representa para o masculino". ${ }^{21} \mathrm{Na}$ introdução da coletânea em que o artigo foi reeditado, no entanto, ela alerta sobre a necessidade de modular seu próprio argumento de que o fetichismo é uma estrutura que desautoriza o conhecimento em favor da crença, em oposição à curiosidade, sugerindo a idéia de uma relação mais dialética entre fetichismo e curiosidade.

Essa qualidade de repensar incansavelmente suas próprias leituras e teorias, buscando soluções mais complexas para seus modelos de análise, é uma das características da reflexão de Laura Mulvey e aparece também fortemente no diálogo entre seus escritos e seus filmes. Em Riddles of the Sphynx, ${ }^{22}$ por exemplo, o tema do Édipo e da esfinge é revisitado para tematizar a questão da maternidade e do triângulo edípico, destacando a relação mãe-filha e a Esfinge como como uma espécie de "mãe mítica", ${ }^{23}$ associada à idéia da "maternidade como mistério" e como "resistência ao patriarcado". No plano formal, ela busca traduzir em linguagem - seu projeto de um contra-cinema, que significa fundamentalmente desmontar os mecanismos de prazer visual do cinema narrativo, provocando um deslocamento do olhar e do sentido. Assim, a fluidez da narrativa do filme tradicional é cortada, em sua parte central, em 13 diferentes fragmentos narrativos; em cada um deles a câmera, posicionada no centro do espaço, realiza o mesmo movimento de 360 graus, em um longo plano-sequência; a cineasta-autora aparece no início e no final do filme, e em pelo menos uma das cenas percebemos a imagem da cinegrafista por trás da câmera, refletida em um espelho, não nos deixando esquecer de que estamos assistindo a um filme. Através de tais intromissões a diretora denuncia $\circ$ processo de fabricação e quebra o ilusionismo da narrativa cinematográfica clássica. Em Frida Kahlo \& Tina Modotti, um documentário feito para acompanhar a exposição de mesmo nome, organizada em Londres em 1983, são expostas duas formas diferentes de olhar, de duas artistas que romperam com a divisão tradicional entre o político e o pessoal. Uma, através das pinturas e de suas auto-imagens, mostrando a beleza do

\footnotetext{
${ }^{21}$ MULVEY, 1996b, p. 62.

${ }^{22}$ Laura MULVEY e Peter WOLLEN, 1976.

${ }^{23}$ SILVERMAN, 1988, p. 130.
} 
corpo quebrado e injuriado. Outra, através da fotografia, representando a beleza de corpos femininos em ação - em diferentes tipos de trabalho. ${ }^{24}$

Nos seus trabalhos mais recentes, e em seu novo livro, que deverá ser lançado até o final de 2005, Laura tem se voltado para a questão das novas tecnologias digitais e como elas podem afetar não somente a realização cinematográfica como também as formas de ver um filme. Mulvey acredita que - inicialmente através da introdução do vídeo e atualmente com a tecnologia dos DVDs - o cinema se mantém mais vivo do que nunca. Tais tecnologias incitam a releitura de filmes clássicos e antigos, e possibilitam outras maneiras de abordálos (através por exemplo da imagem still, aperfeiçoada no DVD); Mulvey também salienta a importância da tecnologia digital para a documentação de conflitos. A portabilidade e facilidade de utilização de câmeras digitais possibilitam uma proximidade e integração entre o diretor e seu objeto sem precedentes na era pré-digital.

Nesta entrevista Laura Mulvey aborda questões relacionadas a seu mais famoso texto, "Visual Pleasure and Narrative Cinema", discutindo o momento em que foi escrito, suas origens e motivações e o subseqüente questionamento de seus argumentos. Ela também nos fala do diálogo entre teoria e prática através do seu trabalho como diretora e de sua busca por um contra-cinema, além de traçar considerações a respeito da obra de diretores que, segunda ela, buscaram alternativas ao cinema clássico hollywoodiano, com atenção especial aos cinemas iraniano e africano. Por fim, Mulvey discute os rumos de suas investigações teóricas e a publicação de seu novo livro tratando de questões relacionadas ao impacto da tecnologia digital.

As preocupações que marcaram seus primeiros trabalhos permanecem, sobretudo aquelas ligadas à necessidade de uma leitura a contrapelo da narrativa cinematográfica clássica, a reflexão crítica sobre as políticas do olhar no cinema e na produção audiovisual e a atenção especial às outras possibilidades de olhar.

\section{Referências bibliográficas}

BUTLER, Judith. "Imitation and Gender Insubordination." In: FUSS, Diana. Inside/Out: Lesbian Theories, Gay Theories. London: Routledge, 1991. p. 13-31.

COOK, Pam, and JOHNSTON, Claire. "The Place of Woman in the Cinema of Raoul Wash." In: PENLEY, Constance (ed.). Feminism and Film Theory. London: Routledge, 1988 [1974]. p. 25-35.

\footnotetext{
${ }^{24}$ MULVEY $~$ WOLLEN, 1983.
} 
DE LAURETIS, Teresa. Alice Doesn't: Feminism, Semiotics, Cinema. Bloomington: Indiana University Press, 1984.

DOANE, Mary Ann. "Film and the Masquerade: Theorizing the Female Spectator." In: SCREEN. Sexual Subjects: a Screen Reader in Sexuality. London: Routledge, 1992. p. 227-243.

KAPLAN, Ann. Women \& Film. Both Sides of the Camera. London: Methuen, 1983.

MULVEY, Laura. "Visual Pleasure and Narrative Cinema." Screen, v. 16, n. 3, p. 6-27, Autumn 1975. "Introduction." In: Visual and Other Pleasures. London: The Macmillan Press Ltd, 1989a. p. vii-xvii. . "Visual Pleasure and Narrative Cinema." In: and Other Pleasures. London: The Macmillan Press Ltd, 1989b. p. 14-26.

. "Afterthoughts on 'Visual Pleasure and Narrative Cinema' inspired by King Vidor's Duel in the Sun (1946)." In: Visual and Other Pleasures. London: The Macmillan Press Ltd, 1989c. p. 29-38. "Fetishisms." In: _. Fetishism and Curiosity. London: $\mathrm{BFI} /$ Indiana Un. Press, 1996a. p. 1-15. "Pandora's Box. Topographies of Curiosity." In:

Fetishism and Curiosity. London: BFI/Indiana Un. Press, $\overline{1996 \mathrm{~b} .}$ p. 53-64.

"Looking at the Past from the Present: Rethinking Feminist Film Theory of the 1970s." Signs. Journal of Women in Culture and Society, v. 30, n. 1, Autumn 2004. p. 1286-1292.

ROSE, Jaqueline. Sexuality in the Field of Vision. London, Verso, 1986.

SCREEN. Sexual Subjects: a Screen Reader in Sexuality. London: Routledge, 1992.

SILVERMAN, Kaja. The Accustic Mirror. The Female Voice in Psychoanalysis and Cinema. Bloomington: Indiana Univ. Press, 1988.

STACEY, Jackie. "Desperately Seeking Difference." In: SCREEN. Sexual Subjects: a Screen Reader in Sexuality. London: Routledge, 1992. p. 244-257.

XAVIER, Ismail (Org.). A experiência do cinema. Rio de Janeiro: Edições Graal/Embrafilme, 1983.

\section{Referências fílmicas}

MULVEY, Laura, and WOLLEN, Peter. Riddles of the Sphynx, UK, 1976. Frida Kahlo \& Tina Modotti, UK, 1983. 